\title{
Algorithms for monitoring warfarin use: Results from Delphi Method
}

\author{
Eunice Kazue Kano ${ }^{1}$, Jessica Bassani Borges ${ }^{1}$, Erika Burim Scomparini ${ }^{1}$, Ana Paula Curi ${ }^{2}$, Eliane Ribeiro ${ }^{1 *}$ \\ ${ }^{1}$ Department of Pharmacy, Faculty of Pharmaceutical Sciences, Universidade de São Paulo (USP), São Paulo, SP, Brazil \\ ${ }^{2}$ School of Arts, Sciences and Humanities, USP, São Paulo, SP, Brazil
}

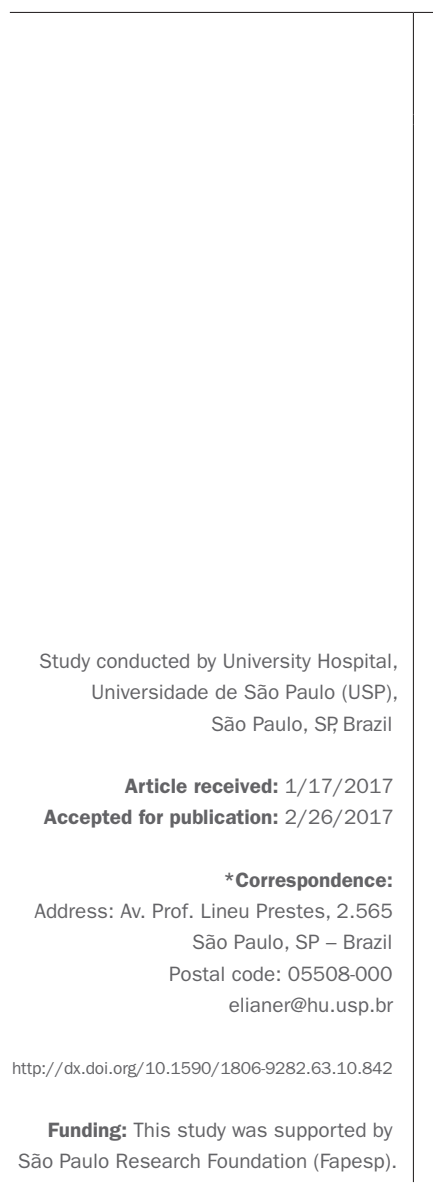

\section{SUMMARY}

Warfarin stands as the most prescribed oral anticoagulant. New oral anticoagulants have been approved recently; however, their use is limited and the reversibility techniques of the anticoagulation effect are little known. Thus, our study's purpose was to develop algorithms for therapeutic monitoring of patients taking warfarin based on the opinion of physicians who prescribe this medicine in their clinical practice. The development of the algorithm was performed in two stages, namely: (i) literature review and (ii) algorithm evaluation by physicians using a Delphi Method. Based on the articles analyzed, two algorithms were developed: "Recommendations for the use of warfarin in anticoagulation therapy" and "Recommendations for the use of warfarin in anticoagulation therapy: dose adjustment and bleeding control." Later, these algorithms were analyzed by 19 medical doctors that responded to the invitation and agreed to participate in the study. Of these, 16 responded to the first round, 11 to the second and eight to the third round. A $70 \%$ consensus or higher was reached for most issues and at least $50 \%$ for six questions. We were able to develop algorithms to monitor the use of warfarin by physicians using a Delphi Method. The proposed method is inexpensive and involves the participation of specialists, and it has proved adequate for the intended purpose. Further studies are needed to validate these algorithms, enabling them to be used in clinical practice.

Keywords: Delphi technique, warfarin, decision-making, medication therapy management.

\section{INTRODUCTION}

Warfarin was commercially introduced in the market in 1954. ${ }^{1}$ Since then, it stands as the most prescribed oral anticoagulant, widely used for prophylaxis and treatment of venous thromboembolism and complications associated with atrial fibrillation and heart valve replacement. ${ }^{2,3}$

New oral anticoagulants, such as direct thrombin inhibitors (DTIs), have been recently approved. However, their use is restricted and reversibility techniques are little known, unlike warfarin, which can be readily reversed by using vitamin K, fresh plasma or recombinant factor VII. ${ }^{46}$ Thus, despite DTIs show predictable pharmacokinetics, which eliminates the need for serum monitoring, they must be monitored as the causative factors for this risk. ${ }^{4,6}$

Other problems related with DTIs include the need for dose adjustments in renal failure patients, the contraindication of use by liver disease patients and drug interactions. ${ }^{47}$
Although some DTIs have shown good risk-benefit ratio, ${ }^{5,8-10}$ more information regarding safety, especially in long-term treatment, is still needed ${ }^{4-7}$ as well as confirmation of the findings obtained so far for DTIs in new clinical trials. ${ }^{11}$

Nevertheless, warfarin, which is inexpensive and easily accessible, shows efficacy above $90 \%$ in preventing further thrombotic episodes, if correctly used, and constitutes an important therapeutic alternative, especially for low-income populations. ${ }^{12}$

Since the pharmacotherapy involving this drug poses risks to patients due to its narrow therapeutic range, information on the use and monitoring of warfarin are essential to establish algorithms or protocols. These documents must serve as guides to therapeutic management by the health team in patient care in order to ensure efficiency and prevent adverse events. ${ }^{13,14}$ 
The protocols must include suggestions for clinical management based on the best scientific evidence available, produced in a structured basis, with common sense and honesty. In the absence of evidence or in situations of conflicting evidence, consensus of experienced experts must be achieved. Therefore, relevant information, appropriate for every situation, are obtained in a systematic basis and become the final link between good quality science and good medical practice. ${ }^{15-17}$

The Delphi Method is a widespread technique, used since the early 1960s for the systematic search of expert consensus on a specific issue. ${ }^{18,19}$ According to this method, a group of experts is consulted on a particular subject, usually related to low-grade scientific evidence that requires a consensus. ${ }^{20}$

In the health sector, the Delphi Method is being increasingly used due to its ease of application, low cost, the fact that it allows equal participation of all individuals involved, in addition to yielding qualified collective opinion on the subject. Despite these advantages, its use is not free from bias, especially if the choice of panelists is not done carefully. It is also important to emphasize that the results obtained using the Delphi Method represent a specific time and the opinion of some professionals, and it is not an absolute truth. ${ }^{21}$

Thus, while warfarin, despite its limitations, still remains as the drug of choice in anticoagulation therapy, being distributed free of charge by the Brazilian public health system, developing new strategies, such as the development and validation of algorithms/protocols for the drug's use, is fundamental to increase therapy safety and effectiveness.

The objective of our study was to develop algorithms for therapeutic monitoring of patients taking warfarin based on the opinion of medical experts.

\section{Method}

The development of the algorithm was performed in two stages: (i) a literature review for developing the algorithm; and (ii) the algorithm's evaluation by medical experts.

In the first stage, a search was performed in the following electronic databases for the years 2008 to present: "PubMed" and "Medline" (International Medical Literature), Lilacs (Latin American and Caribbean Literature on Health Sciences), and Embase (International Biomedical Literature). The UptoDate (Wolters Kluwer Health) evidence-based clinical decisions database was also used. The combination of the following terms was applied: warfarin, algorithm, therapeutic, dose adjustment, DRR, INR, drug monitoring, dose and response.
Full-text publications available in Portuguese, English or Spanish on human studies presenting primary data, or review articles on the subject were included. In addition to this strategy, some articles were selected from references of articles found in the databases searched. From the analysis of the articles, we elaborated the first algorithm and questions to be responded by medical experts in anticoagulation according to the Delphi Method.

The questions were sent to a group of experts, anonymously and systematically. Three rounds of questionnaires containing questions that did not reach consensus in the previous stage were applied.

Anonymity, the lack of personal contact among respondents, the statistical representation of the distribution of results, and the feedback to the group for reassessment of responses in subsequent rounds were the main features used from said method. ${ }^{20}$

Our project was approved by the Research Ethics Committee of the University Hospital of University of São Paulo, number 764/07 and SISNEP 0048.0.198.01807; all respondents signed an Informed Consent (IC) form.

Nineteen (19) medical doctors experts in warfarin anticoagulation, from different specialties and different institutions, all linked to teaching hospitals in São Paulo, were invited to participate in the research. The medical experts were selected after curriculum review, contacts in university hospitals and search on university websites.

The inclusion criteria were:

- being a general practitioner, cardiologist, hematologist and/or vascular surgeon;

- working in universities and/or hospitals in the city of São Paulo that conduct scientific research;

- being experienced in the clinical use of warfarin.

The first contact with medical experts was performed over the phone, and then an invitation letter containing the study objectives and responsibilities of the respondents was electronically sent. In cases where the physician agreed to participate in the study, a date was scheduled so that the researcher could provide more details on the project and collect a signed IC form.

\section{Elaboration and application of questionnaires}

For the first questionnaire (Q1), 25 questions were elaborated about conflicting theoretical data to be answered in a maximum of 30 minutes. Q1 was developed in electronic and printed forms, with open fields for answers only, and was divided into four parts:

a. Introduction and general guidelines. 
b. Personal data such as age, gender, specialty, and type of service in which he/she worked at the time were requested.

c. Questions about conflicting data, and about the evaluation algorithm itself.

d. Generic questions, in order to evaluate the usefulness of the algorithm in medical practice.

From the analysis of Q1 responses, a second questionnaire (Q2) was elaborated and sent to those same experts, this time divided into two parts: a) letter to the expert; b) multiple-choice questions which did not reach consensus in Q1, with a graph showing the percentage results obtained in Q1, so that respondents could know the answer trend for each question. Then, the third questionnaire (Q3) was elaborated, containing questions that did not reach consensus in Q2, divided into two parts, with an explanatory letter and multiple-choice questions. After reviewing the responses in Q3, a letter expressing our gratitude and containing feedback from the study results was elaborated and sent to each respondent.

Quantitative analysis of the responses obtained in Q1, Q2 and Q3 was performed by using basic descriptive statistics, including means, medians, and standard deviation. For qualitative data, the responses were expressed in percentage (response distribution frequencies). Consensus was achieved whenever a minimum of $70 \%$ of respondents chose the same alternative.

\section{Results}

Development of algorithm for therapeutic drug monitoring in patients taking warfarin

Based on the analyzed articles, two algorithms were developed: "Recommendations for the use of warfarin in anticoagulation therapy" (Figure 1A) and "Recommendations for the use of warfarin in anticoagulation therapy: dose adjustment and bleeding control” (Figure 1B).

\section{Algorithm evaluation by medical experts by Delphi Method}

Figure 2 shows the flowchart of the Delphi Method used for applying the questionnaires to medical experts.

\section{Medical experts participating in the study}

Most medical experts (63\%) were male, aged $41.5 \pm 10.13$ (mean $\pm \mathrm{SD}$ ) years, with a length of education of 14.46 years after medical internship. Nineteen percent (19\%) worked in public institutions, $6.25 \%$ in private institutions, and $75 \%$ in both.

These experts represented the following medical areas: $68 \%$ cardiology, $16 \%$ hematology, $11 \%$ general practice and $5 \%$ vascular surgery.

\section{Algorithms evaluation}

In the first round, out of 19 questions sent, 16 were answered and sent back to us, representing a loss of $15.79 \%$.

Regarding miscellaneous data, all the doctors reported that the algorithms are useful tools for warfarin dose adjustment in clinical practice. Sixty-three percent (63\%) considered it important to apply the algorithm in public and private hospitals, and medical offices.

Based on the results observed in this first round, it became clear that the optimum dosage of warfarin is controversial. The doubts raised and the lack of standardization are so great that $100 \%$ of the doctors who answered the questionnaire considered the use of the algorithm as an important decision tree for the prescription of warfarin dose.

The conflicting questions in Q1 were classified according to the percentage found: with consensus and without consensus. Those questions without consensus in the first round were repeated in the second round (Q2), and those for which no consensus was obtained in the second round were repeated once again in the third round (Q3). Table 1 shows the questions contained in all questionnaires as well as their responses.

In Table 1, it is noted that, for 18 conflicting questions in the first round, subdivided into 27 questions, consensus was reached with $70 \%$ or higher agreement for 17 $(62.96 \%=17 / 27)$.

Q2 comprised ten multiple-choice questions sent to 16 experts who participated in the first round. Of these, 11 responded to the questions. Therefore, there was a loss of $31.25 \%$ compared to the previous round, and $42.10 \%$ of the total.

In three $(3 / 12=25 \%)$ out of 12 questions, consensus was reached with $\geq 70 \%$ agreement; $\mathrm{Q} 3$ was sent to the 11 respondents from the previous round, including eight questions that achieved no consensus in the second round, as well as frequency graphs for the responses in the previous questionnaire.

Eight experts responded to this round $(72.72 \%=8 / 11)$. Based on the previous round, there was a loss of $27.27 \%$ of respondents. For all the rounds, the registered loss was $57.89 \%(8 / 19)$.

Consensus of $\geq 70 \%$ was reached for two questions, and at least $50 \%$ for the other six.

Based on the three rounds, only the algorithm "Recommendation for using warfarin in anticoagulation therapy: bleeding control" was changed; pending questions and those which did not reach consensus with agreement of $70 \%$ or higher were underlined; and those showing agreement $>50 \%$ are described in italics (Figure 3 ). 
TABLE 1 Questions contained in Q1, Q2 and Q3 and responses obtained from medical experts after their application in first, second and third rounds. The responses were classified according to their percentage of agreement.

\section{Questions}

First Round

Response

Amount (\%) Consensus

(responses/ (> 70\%)

doctors)

1. What is the initial dose of warfarin for an adult

$5 \mathrm{mg} /$ day

94\% $(15 / 16) \quad$ Yes

outpatient who has never taken warfarin and whose

desirable INR range for therapy is between 2 and 3?

2. And for those patients in poor nutritional status, the elderly, patients with liver disease or those at high risk of bleeding?

$2.5 \mathrm{mg} /$ day

$06 \%(16 / 01)$

\begin{tabular}{l}
$2.5 \mathrm{mg} /$ day \\
\hline $2.0 \mathrm{mg} /$ day \\
\hline $5 \mathrm{mg} /$ day \\
\hline would not use
\end{tabular}

3. Is there any difference in the initial dose of warfarin between inpatients and outpatients?

No

*4. After how many days from taking the initial dose should the first INR testing be done to assess the patient?

No

$75 \%(12 / 16) \quad$ Yes

$13 \%(02 / 16)$

$06 \%(16 / 01)$

Yes 25\%(04/16)

5 days

3 days

$50 \%(08 / 16) \quad$ No

What should be the frequency of INR monitoring until

the desired range is reached?

7 days

$25 \%(04 / 16)$

weekly

$25 \%(04 / 16)$

every 2-3 days

$63 \%(10 / 16) \quad$ No

Daily

$31 \%(05 / 16)$

*6. Is there a preferable period in a day to collect blood for INR testing?

Yes, morning.

$06 \%(16 / 01)$

7. What should be the frequency for monitoring of INR after reaching the therapeutic range?

No

$56 \%(09 / 16) \quad$ No

monthly $44 \%(07 / 16)$ $81 \%(13 / 16) \quad$ Yes

weekly

$13 \%(02 / 16)$

weekly

$06 \%(16 / 01)$

8. When should dose adjustment be done?

\begin{tabular}{|c|c|c|}
\hline $\begin{array}{l}\text { If INR is out of the therapeutic range, after 4-6 } \\
\text { days from the beginning of therapy. }\end{array}$ & $75 \%(12 / 16)$ & Yes \\
\hline $\begin{array}{l}\text { If INR is out of the therapeutic range, in two } \\
\text { consecutive measurements; }\end{array}$ & $44 \%(07 / 16)$ & \\
\hline $\begin{array}{l}\text { If after } 3 \text { days using warfarin, the patient has not } \\
\text { yet reached the expected INR range }\end{array}$ & $06 \%(16 / 01)$ & \\
\hline $\begin{array}{l}I N R \leq 1.5 / 1.5<I N R \leq 1.8 / 1.9 \leq I N R<3.2 / 3.2 \leq \\
I N R<5.0 / I N R \geq 5.0\end{array}$ & $25 \%(04 / 16)$ & Yes \\
\hline $\begin{array}{l}1.0 \leq \mathrm{INR}<2.0 / 3.0<\mathrm{INR}<6.0 / 6.0 \leq \mathrm{INR}<10.0 / \\
10.0 \leq \mathrm{INR} \leq 18.0 / \mathrm{INR}>18.0\end{array}$ & $69 \%(11 / 16)$ & \\
\hline $\begin{array}{l}I N R \leq 1.5 / 1.51 \leq \mathrm{INR} \leq 1.99 / 2.0 \leq \mathrm{INR} \leq 3.0 / \\
3.01 \leq \mathrm{INR}<3.99 / 4.0 \leq \mathrm{INR} \leq 4.99 / 5.0 \leq \mathrm{INR} \leq \\
8.99 / \mathrm{INR} \geq 9.0\end{array}$ & $13 \%(02 / 16)$ & \\
\hline other & $25 \%(04 / 16)$ & \\
\hline No answer & $13 \%(02 / 16)$ & \\
\hline
\end{tabular}

**9. Which INR ranges would determine an action for changing the dose?

$13 \%(02 / 16)$

Questions 10 to 16 refer to an outpatient whose therapeutic INR range is between 2 and 3 , and in none of the cases the patient has shown evidence of hemorrhage.

*10. If a patient shows an INR lower than or equal to 1.5 what would the dose adjustment be?

\begin{tabular}{ll} 
Increase 20\% & $38 \%(06 / 16)$ \\
\hline Increase 33\% & $31 \%(05 / 16)$ \\
\hline Double the dose & $06 \%(16 / 01)$ \\
\hline other & $25 \%(04 / 16)$ \\
\hline
\end{tabular}


TABLE 1 Questions contained in Q1, Q2 and Q3 and responses obtained from medical experts after their application in first, second and third rounds. The responses were classified according to their percentage of agreement.

\section{Questions}

First Round

\begin{tabular}{|c|c|c|c|}
\hline & Response & $\begin{array}{l}\text { Amount (\%) } \\
\text { (responses/ } \\
\text { doctors) }\end{array}$ & $\begin{array}{l}\text { Consen- } \\
\text { sus } \\
(>70 \%)\end{array}$ \\
\hline 10a. After how many days would you reassess patient status? & 5-7 days & $100 \%(16 / 16)$ & Yes \\
\hline \multirow[t]{4}{*}{ *11. What if $1.5 \leq \mathrm{INR} \leq 1.8 ?$} & Increase $15 \%$ & $38 \%(06 / 16)$ & \multirow[t]{4}{*}{ No } \\
\hline & Increase $10 \%$ & $31 \%(05 / 16)$ & \\
\hline & Recollect after a week & $06 \%(16 / 01)$ & \\
\hline & Other & $25 \%(04 / 16)$ & \\
\hline \multirow{2}{*}{$\begin{array}{l}\text { 11a. After how many days would you reassess patient } \\
\text { status? }\end{array}$} & 5 to 7 days & $88 \%(14 / 16)$ & \multirow[t]{2}{*}{ Yes } \\
\hline & 14 days & $13 \%(02 / 16)$ & \\
\hline \multirow[t]{2}{*}{ 12. What if $1.8 \leq \mathrm{INR} \leq 3.2$ ? } & Do not change the dose & $81 \%(13 / 16)$ & \multirow[t]{2}{*}{ Yes } \\
\hline & Reduce the dose by $25 \%$ & $13 \%(02 / 16)$ & \\
\hline \multirow{3}{*}{$\begin{array}{l}\text { *12a. After how many days would you reassess patient } \\
\text { status? }\end{array}$} & 7-10 days & $44 \%(07 / 16)$ & \multirow[t]{3}{*}{ No } \\
\hline & 30 days & $44 \%(07 / 16)$ & \\
\hline & other & $13 \%(02 / 16)$ & \\
\hline \multirow[t]{3}{*}{ *13. What if $3.2 \leq \mathrm{INR}<4.9$ ? } & $\begin{array}{l}\text { Discontinue the next dose and reintroduce } \\
\text { warfarin at a weekly dose reduced by } 10-20 \% \text {. }\end{array}$ & $50 \%(08 / 16)$ & \multirow[t]{3}{*}{ No } \\
\hline & $\begin{array}{l}\text { Discontinue the next dose and reintroduce } \\
\text { warfarin at a weekly dose reduced by } 33 \% \text {. }\end{array}$ & $44 \%(07 / 16)$ & \\
\hline & $\begin{array}{l}\text { Discontinue for three days and reintroduce } \\
\text { warfarin at a dose reduced by } 25-50 \% \text {. }\end{array}$ & $06 \%(16 / 01)$ & \\
\hline \multirow{3}{*}{$\begin{array}{l}\text { 13a. After how many days would you reassess patient } \\
\text { status? }\end{array}$} & 5-7 Days & $88 \%(14 / 16)$ & \multirow[t]{3}{*}{ Yes } \\
\hline & 2-5 days & $06 \%(16 / 01)$ & \\
\hline & 14 days & $06 \%(16 / 01)$ & \\
\hline \multirow[t]{6}{*}{ *14. What if $5.0 \leq \mathrm{INR}<9.0$, with no evidence of bleeding } & $\begin{array}{l}\text { Discontinue warfarin and assess the need to give } \\
\text { vitamin K orally ( } 2-4 \mathrm{mg}) \text {. After } 24 \text { hours, if there } \\
\text { is no more risk of bleeding, reintroduce warfarin } \\
\text { with reduction of } 15 \% \text { in the weekly dose. }\end{array}$ & $38 \%(6 / 16)$ & \multirow[t]{6}{*}{ No } \\
\hline & $\begin{array}{l}\text { Discontinue the next three doses and then restart } \\
\text { the treatment at a dose } 33 \% \text { lower }\end{array}$ & $38 \%(6 / 16)$ & \\
\hline & $\begin{array}{l}\text { Discontinue the next dose and then restart the } \\
\text { treatment at lower doses until reach the } \\
\text { therapeutic INR }\end{array}$ & $06 \%(16 / 01)$ & \\
\hline & $\begin{array}{l}\text { Discontinue until desirable INR and reintroduce at } \\
\text { reduced dose }\end{array}$ & $06 \%(16 / 01)$ & \\
\hline & $\begin{array}{l}\text { Discontinue until desirable INR, reassess in 2-3 } \\
\text { days, and reintroduce at reduced dose }\end{array}$ & $06 \%(16 / 01)$ & \\
\hline & $\begin{array}{l}\text { Discontinue warfarin and assess the need to give } \\
\text { vitamin K orally ( } 2-4 \mathrm{mg}) \text {. After } 24 \text { hours, if there } \\
\text { is no more risk of bleeding, reintroduce warfarin } \\
\text { with reduction of } 50 \% \text { in the weekly dose. }\end{array}$ & $06 \%(16 / 01)$ & \\
\hline \multirow{4}{*}{$\begin{array}{l}\text { *14a. After how many days would you reassess patient } \\
\text { status? }\end{array}$} & 3-7 days & $56 \%(9 / 16)$ & \multirow[t]{4}{*}{ No } \\
\hline & 2 days & $25 \%(04 / 16)$ & \\
\hline & 24 hours & $13 \%(02 / 16)$ & \\
\hline & No answer & $06 \%(16 / 01)$ & \\
\hline
\end{tabular}


TABLE 1 Questions contained in Q1, Q2 and Q3 and responses obtained from medical experts after their application in first, second and third rounds. The responses were classified according to their percentage of agreement.

\section{Questions}

First Round

Response

Amount (\%) Consen-

(responses/ sus

doctors) (> 70\%)

15. And if INR > 10.0, with no evidence of bleeding?

Discontinue warfarin until INR reduction and give $75 \%(12 / 16) \quad$ Yes

5 to $10 \mathrm{mg}$ of vitamin K orally.

Other $31 \%(05 / 16)$

*15a. After how long would you reassess patient status?

24 hours

Every 2 Days

$69 \%(11 / 16) \quad$ No

16. In case there is evidence of minor bleeding, what is the dose of vitamin K?

Discontinue warfarin, give vitamin K $10 \mathrm{mg}$ and, if $\quad 94 \%(15 / 16) \quad$ Yes necessary, supplement with fresh plasma or prothrombin concentrate.

Discontinue warfarin, give vitamin $\mathrm{K}$, and restart later $06 \%(16 / 01)$

\begin{tabular}{lll}
\hline $\begin{array}{l}\text { 16a. After how many days would you reassess patient } \\
\text { status? }\end{array}$ & 12 hours & $75 \%(12 / 16)$ \\
\cline { 2 - 3 } & 24 hours & $25 \%(04 / 16)$ \\
\hline
\end{tabular}

The question below refers to the case of a patient showing evidences of major bleeding:

17. Sugiro: How would you manage warfarin therapy?

Discontinue warfarin, give prothrombin complex

and vitamin K $10 \mathrm{mg} 75 \%(12 / 16)$

other 25\%(04/16)

17a. After how long should the patient be reassessed?

other

$81 \%(13 / 16) \quad$ Yes

12 hours $19 \%(3 / 16)$

The question below refers to the case of a patient experiencing life-threatening bleeding:

1 day $75 \%(12 / 16) \quad$ Yes

18. Sugiro: How would you manage warfarin therapy? Discontinue warfarin, give prothrombin complex and vitamin $\mathrm{K} 10 \mathrm{mg}$

18a. After how many days would you reassess patient status?

Other $25 \%(04 / 16)$

\begin{tabular}{ll}
12 hours & $25 \%(04 / 16)$ \\
\cline { 1 - 1 } 1 day & $81 \%(13 / 16)$ \\
Yes
\end{tabular}

Questions

Second Round

Response Amount (\%) Consensus (responses) (> 70\%) doctors)

**1. How many days after taking the initial dose should the first INR testing be done to assess the patient?

**2. What should be the frequency of INR monitoring until the desired range is reached?

**3. Is there a preferable period within the day to collect blood for INR testing?

4. When should dose adjustment be done (tick all possible alternatives)?

$27 \%(3 / 11)$

\begin{tabular}{l}
3 days \\
\hline days \\
\hline week
\end{tabular}

No $64 \%(7 / 11)$

If the INR is out of therapeutic range after 4-6 $100 \%(11 / 11) \quad$ Yes

The following questions refer to an outpatient whose therapeutic INR range is between 2 and 3 , and in none of the cases the patient shows evidence of hemorrhage.

**5. If a patient shows INR lower than 1.5 , which would be the dose adjustment?

\begin{tabular}{ll} 
Increase by $20 \%$ & $27 \%(3 / 11)$ \\
\cline { 1 - 2 } Double the daily dose & $9 \%(1 / 11)$ \\
\hline Increase by 33\% & $55 \%(6 / 11)$ \\
\hline Other & $9 \%(1 / 11)$ \\
\hline
\end{tabular}


TABLE 1 Questions contained in Q1, Q2 and Q3 and responses obtained from medical experts after their application in first, second and third rounds. The responses were classified according to their percentage of agreement.

\section{Questions}

First Round

Response

\begin{tabular}{|c|c|c|c|}
\hline & & $\begin{array}{l}\text { (responses/ } \\
\text { doctors) }\end{array}$ & $\begin{array}{l}\text { sus } \\
(>70 \%)\end{array}$ \\
\hline \multirow[t]{2}{*}{$* * 6$. What if $1.5 \leq \mathrm{INR} \leq 1,8$} & Increase by $15 \%$ & $64 \%(7 / 11)$ & \multirow[t]{2}{*}{ No } \\
\hline & Increase by $25 \%$ & $36 \%(4 / 11)$ & \\
\hline \multirow{2}{*}{$\begin{array}{l}\text { 7. After how many days would you reassess the status of } \\
\text { a patient showing } 1.9 \leq \mathrm{INR} \leq 3.4 \text { ? }\end{array}$} & 7-14 days & $73 \%(8 / 11)$ & \multirow[t]{2}{*}{ Yes } \\
\hline & 30 days & $27 \%(3 / 11)$ & \\
\hline \multirow[t]{2}{*}{$* * 8$. What if $3.4 \leq \mathrm{INR} \leq 5.0$} & $\begin{array}{l}\text { Suspend the next dose and reintroduce warfarin } \\
\text { with a weekly dose reduced by } 10-20 \%\end{array}$ & $55 \%(6 / 11)$ & \multirow[t]{2}{*}{ No } \\
\hline & $\begin{array}{l}\text { Suspend the next dose and reintroduce warfarin } \\
\text { with a weekly dose reduced by } 33 \%\end{array}$ & $45 \%(5 / 11)$ & \\
\hline \multirow[t]{3}{*}{$\begin{array}{l}\text { **9. What if } 5.0 \leq \mathrm{INR} \leq 9.0 \text { with patient under risk to } \\
\text { develop hemorrhage in the next } 30 \text { days? }\end{array}$} & $\begin{array}{l}\text { Discontinue treatment for the } 3 \text { next doses and } \\
\text { then restart therapy at a dose } 33 \% \text { lower }\end{array}$ & $45 \%(5 / 11)$ & \multirow[t]{3}{*}{ No } \\
\hline & $\begin{array}{l}\text { Discontinue warfarin treatment and assess the } \\
\text { need for oral administration of vitamin } \mathrm{K}(2-4 \mathrm{mg}) \text {. } \\
\text { After } 24 \text { hours, if there is no more risk of bleeding, } \\
\text { reintroduce warfarin with } 15 \% \text { reduction }\end{array}$ & $45 \%(5 / 11)$ & \\
\hline & Other & $9 \%(1 / 11)$ & \\
\hline \multirow{3}{*}{$\begin{array}{l}\text { **9a. After how many days would you reassess patient } \\
\text { status? }\end{array}$} & $24 \mathrm{~h}$ & $55 \%(6 / 11)$ & \multirow[t]{3}{*}{ No } \\
\hline & 2 days & $9 \%(1 / 11)$ & \\
\hline & 3-7 days & $36 \%(4 / 11)$ & \\
\hline \multirow[t]{2}{*}{ 10. What if $9.0 \leq \mathrm{INR} \leq 20.0$ ? } & $\begin{array}{l}\text { Discontinue warfarin therapy until reduction of INR. } \\
\text { Reintroduce therapy at low-dose of warfarin and restart } \\
\text { dose titration. If required, give vitamin } \mathrm{K}(5-10 \mathrm{mg})\end{array}$ & $73 \%(8 / 11)$ & \multirow[t]{2}{*}{ Yes } \\
\hline & Other & $27 \%(3 / 11)$ & \\
\hline \multirow{2}{*}{$\begin{array}{l}\text { **10a. After how many days would you reassess patient } \\
\text { status? }\end{array}$} & Daily & $64 \%(7 / 11)$ & \multirow[t]{2}{*}{ No } \\
\hline & Every 2 Days & $36 \%(4 / 11)$ & \\
\hline \multirow[t]{2}{*}{ Questions } & Third Round & & \\
\hline & Response & $\begin{array}{l}\text { Amount (\%) } \\
\text { (responses/ } \\
\text { doctors) }\end{array}$ & $\begin{array}{l}\text { Consensus } \\
(>70 \%)\end{array}$ \\
\hline \multirow{2}{*}{$\begin{array}{l}\text { 1. Is there a preferable period during the day to collect } \\
\text { blood for INR testing? }\end{array}$} & Yes, morning & $50 \%(4 / 8)$ & \multirow[t]{2}{*}{ No } \\
\hline & No, but always in the same period & $50 \%(4 / 8)$ & \\
\hline
\end{tabular}

Questions 2 to 5 refer to an outpatient whose therapeutic INR range is between 2 and 3 , and in none of the cases the patient shows evidence of hemorrhage.

\begin{tabular}{|c|c|c|c|}
\hline \multirow{2}{*}{$\begin{array}{l}\text { 2. If a patient shows INR lower than } 1.5 \text {, which would be } \\
\text { the dose adjustment? }\end{array}$} & Increase by $20 \%$ & $38 \%(3 / 8)$ & \multirow[t]{2}{*}{ No } \\
\hline & Increase by $33 \%$ & $62 \%(5 / 8)$ & \\
\hline \multirow[t]{3}{*}{ 3. What if $1.5 \leq \mathrm{INR} \leq 1.8$} & Increase by $15 \%$ & $38 \%(3 / 8)$ & \multirow[t]{3}{*}{ No } \\
\hline & Increase by $25 \%$ & $50 \%(4 / 8)$ & \\
\hline & Other & $12 \%(1 / 8)$ & \\
\hline \multirow[t]{4}{*}{ 4. What if $3.2 \leq \mathrm{INR} \leq 4.9$} & Suspend the next dose and reintroduce warfarin & $62 \%(5 / 8)$ & \multirow[t]{4}{*}{ No } \\
\hline & with a weekly dose reduced by $10-20 \%$ & & \\
\hline & $\begin{array}{l}\text { Suspend the next dose and reintroduce warfarin } \\
\text { with a weekly dose reduced by } 33 \%\end{array}$ & $25 \%(2 / 8)$ & \\
\hline & Other & $12 \%(1 / 8)$ & \\
\hline
\end{tabular}


TABLE 1 Questions contained in Q1, Q2 and Q3 and responses obtained from medical experts after their application in first, second and third rounds. The responses were classified according to their percentage of agreement.

\section{Questions}

First Round

Response

Amount (\%) Consen-

(responses/ sus

doctors) (>70\%)

5. What if $5.0 \leq \mathrm{INR} \leq 9.0$ with no evidences of bleeding?

Discontinue the next 3 doses and then restart the

$50 \%(4 / 8)$

No

therapy at a dose $33 \%$ lower

Discontinue warfarin treatment and assess the

$38 \%(3 / 8)$

need for oral administration of vitamin K (1-2 mg).

After 24 hours, if there is no more risk of bleeding,

reintroduce warfarin with $15 \%$ reduction

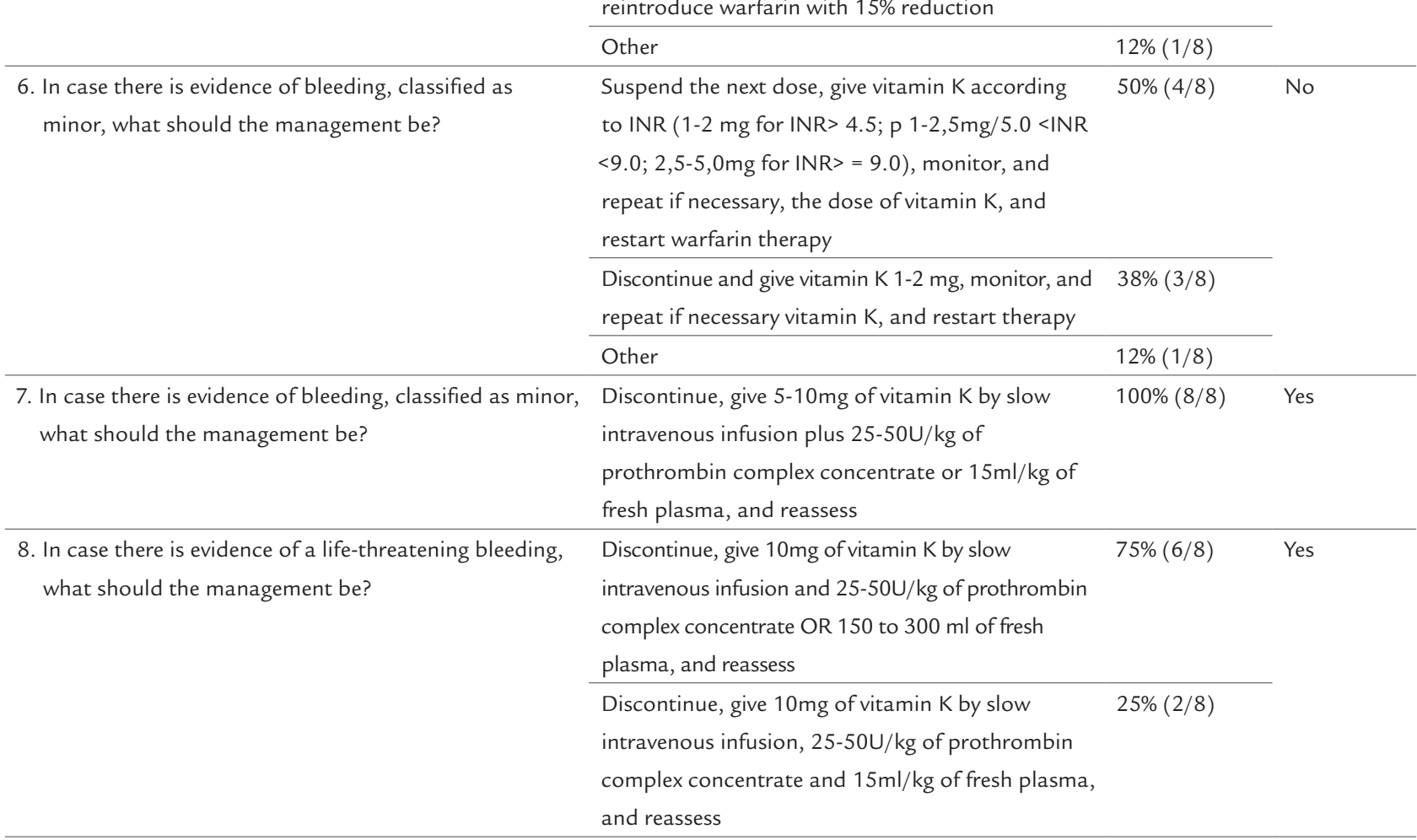

* Questions contained in the questionnaire of the second round.

** Questions contained in the questionnaire of the third round. 


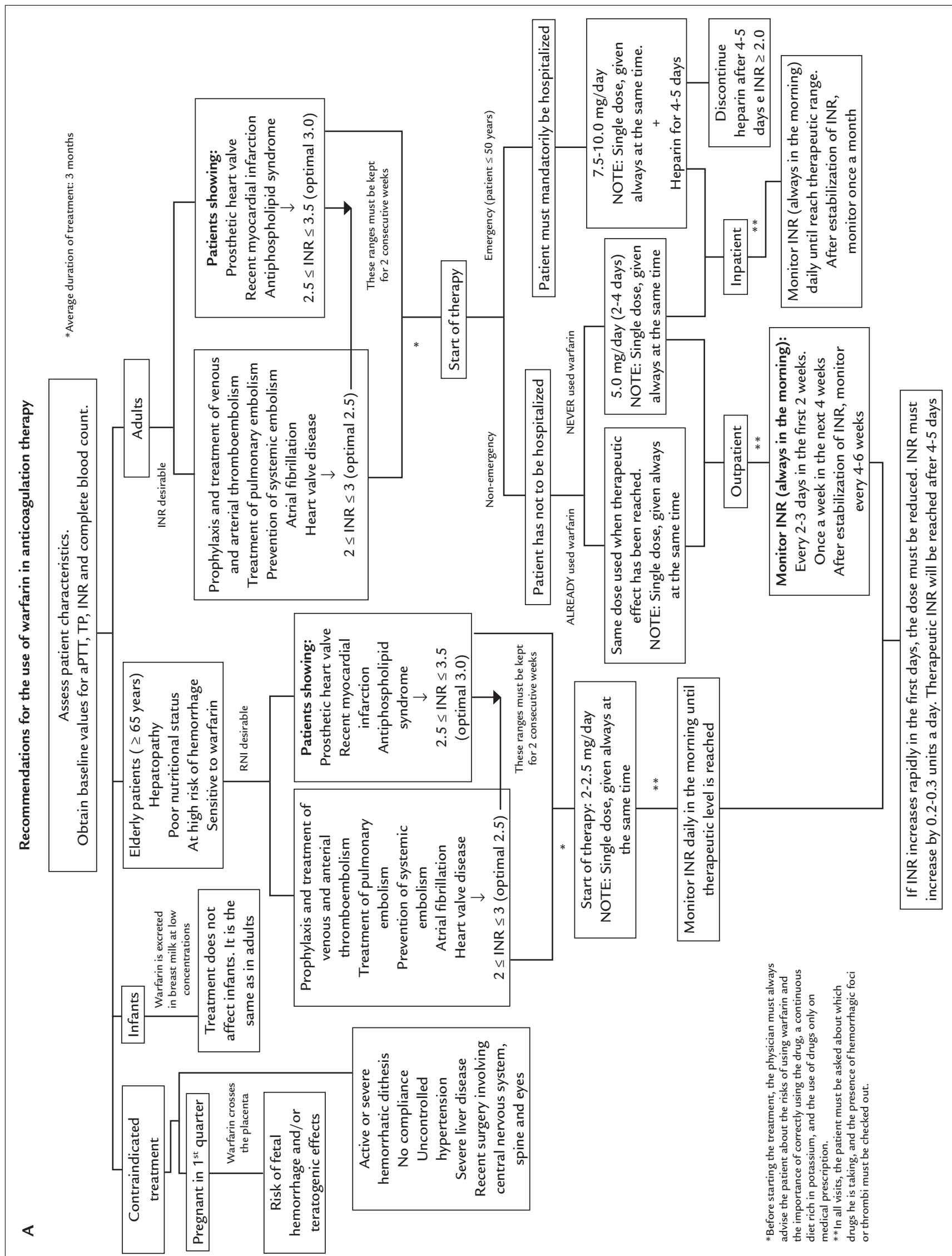




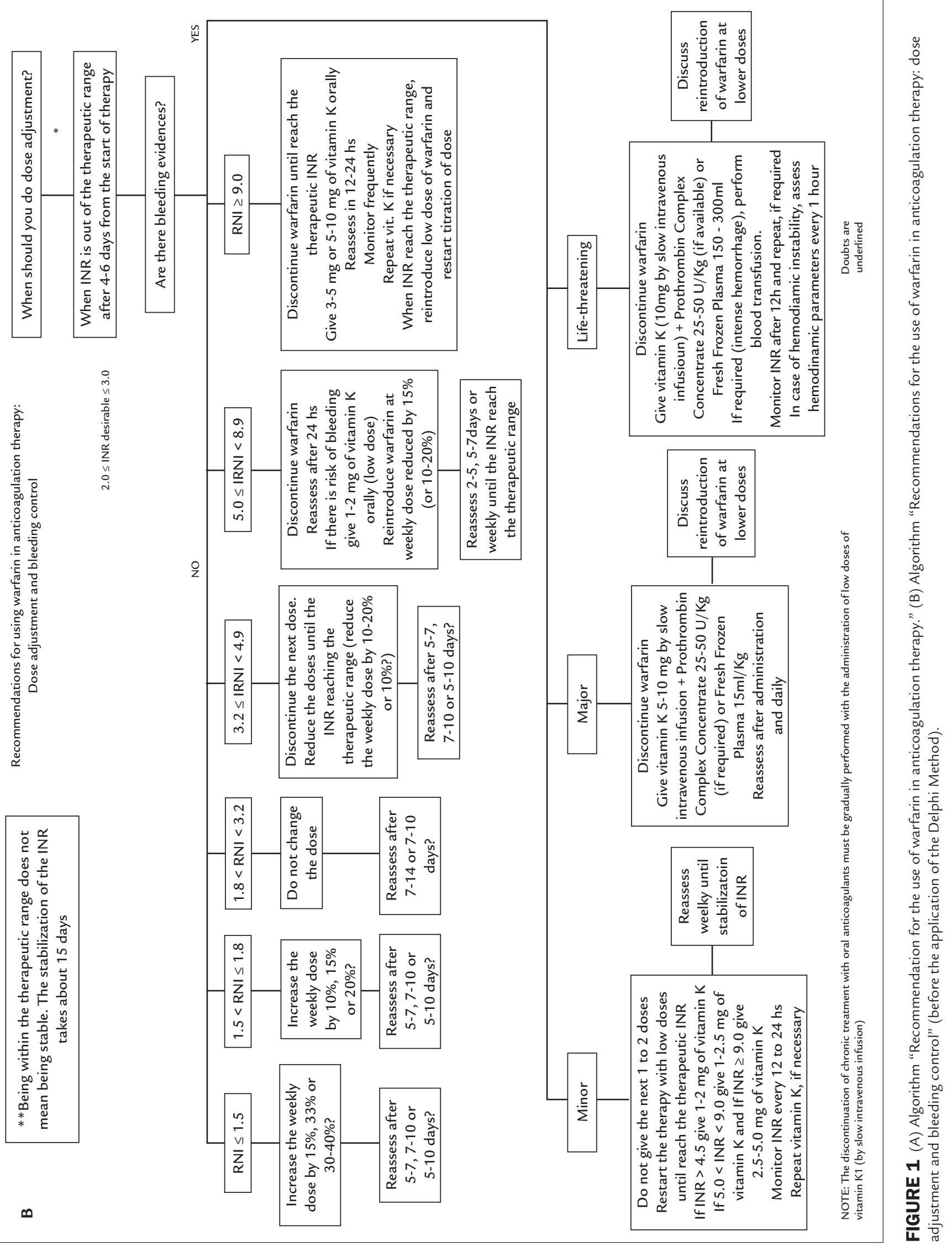




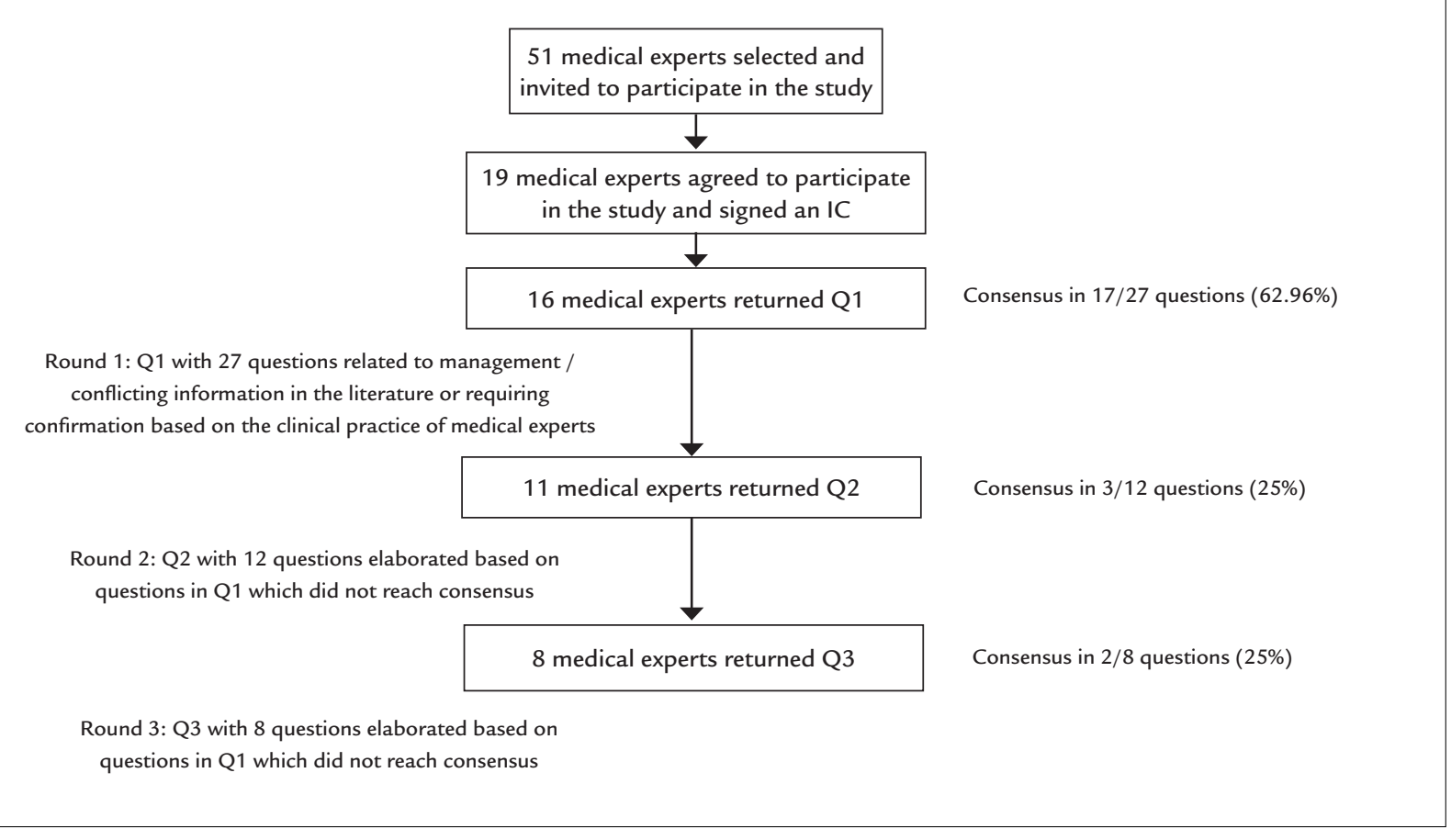

FIGURE 2 Flowchart of Delphi Method for the application of questionnaires to medical doctors specialized in anticoagulation with warfarin.

\section{Discussion}

Even with the introduction of new oral anticoagulants, ${ }^{10}$ warfarin still stands as the oral anticoagulant of choice for thromboembolic events due to several factors: (i) deep knowledge of various clinical indications; (ii) accumulation of safety data; (iii) availability of antidote; (iv) possibility of monitoring with a simple blood sample; (v) low cost of treatment; (vi) free distribution by the Brazilian public health system; (vii) availability of pharmacogenetic studies for optimization of drug therapy.

Pharmacotherapy with warfarin requires careful and continuous monitoring of the patient to minimize the risk of bleeding and thrombosis, since the dose required for proper anticoagulation is highly variable. One measure to minimize the risks and enhance patient safety is the application of clinical and pharmacogenetic algorithms to establish the optimal dose.

The use of algorithms based on pharmacogenetics for individualization of dose regimen for warfarin is described by several authors, ${ }^{22-25}$ since genotype is the main determinant of the required warfarin dose and the risk of bleeding, especially in the early months of therapy. ${ }^{26}$

Clinical studies have shown that the use of genotype to determine warfarin dose generates variability of results, especially because of the complexity of interrelations between genetic and non-genetic factors. ${ }^{3,23}$ Meta-analyses have shown that the dose-adjustment strategy guided by genotype does not improve anticoagulation control at the beginning of therapy compared to adjustments based on clinical data. ${ }^{24,27}$ Thus, studies conducted by Johnson and Cavallari ${ }^{3}$ indicated that the algorithms based on pharmacogenetics to warfarin are "population-specific" and generally achieve better responses in European populations, and cannot be extrapolated for mixed samples. The Brazilian population is highly heterogeneous and this scenario is challenging for pharmacogenetic studies. ${ }^{23}$

Additionally, the amount of information related to pharmacogenomics of warfarin, especially from wellconducted studies, still remains poor and inconsistent. ${ }^{2,28}$

In times of cost reductions and patient-centered care, clinical practice must always aim at reducing adverse events and improving patient quality of life, as well as optimize the use of financial resources. Cost-effectiveness analyses of dose adjustment guided by genotype for warfarin are inconclusive. In this context, it seems unlikely that a dose adjustment guided by genotype for patients who will start treatment with warfarin will become the standard in the near future. ${ }^{27}$ For Stergiopoulos and Brown, ${ }^{27}$ it is more feasible to allocate financial resources for the establishment of better infrastructure for INR testing, implementation of validated clinical protocols of anticoagulation and promotion of patient compliance.

Traditionally, pharmacotherapy with warfarin starts with a non-standardized dose, which is adjusted based on 


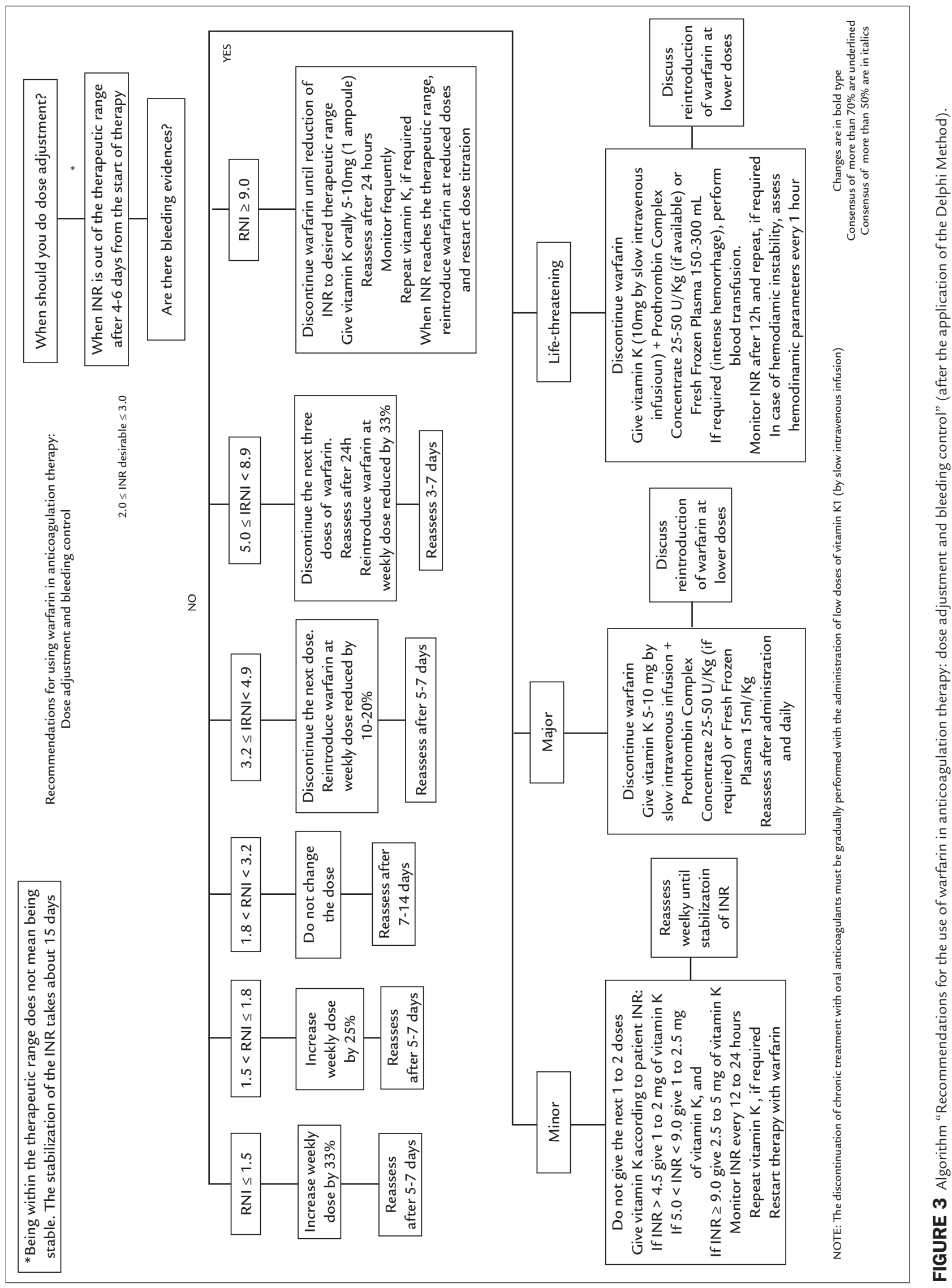


the INR of prothrombin time. A literature search indicated that there are disagreements regarding the initial dose, the time and frequency of INR monitoring, and dose adjustment in case of some adverse event. These issues were evaluated in our study by means of Delphi Method.

In our study, experts were judiciously selected from different specialties and linked to private and/or public hospitals to ensure group diversity. According to Keeney et al., ${ }^{29}$ the selection of experts (or panelists) is one of the critical points of this method, since the result of the study will critically depend on the opinion of the respondents. They must be really involved with the subject of the pan$\mathrm{el}$ and represent the opinion of a population.

Regarding panel size, the literature does not determine the ideal number of panelists, since the result does not depend on the statistical power of the sample size. Nevertheless, it suggests the inclusion of 10-18 experts. ${ }^{30}$ Furthermore, the size and composition of the panel depends on the nature of the research. ${ }^{31}$ Our study started with 19 panelists, which is a number higher than the recommended considering potential dropouts.

The loss of follow-up by panelists along the rounds may restrict the application of the Delphi Method. Considering this, some care has been taken in our study, such as providing speedy feedback of the results of each round, and encouraging non-respondents to respond through systematic follow-up contacts. The peak loss in our study was recorded in the second round, $31.25 \%$, and according to Keeney et al. ${ }^{29}$ the optimal maximum loss of respondents at follow-up must be $30 \%$ in each round of the questionnaire.

Regarding the number of questions that composed the questionnaire, the first round, which included the largest number of questions, contained 27 items, which is an adequate number to ensure the compliance of respondents. According to Wright and Giovinazzo, ${ }^{20}$ questions should be mainly composed of alternatives, so that the total time to answer them does not exceed 30 minutes.

The number of rounds in the studies published in the literature varies from 1 to more than 5 and most of them include 2-3 rounds. ${ }^{32}$ In our study, a 3-round design was adopted.

The responses obtained from the questionnaires must be evaluated based on the agreement or consensus among the consulted experts, but the definition of whatever constitutes consensus is controversial. Some authors suggest as consensus $51 \%$ of agreement among respondents regarding a certain answer, but others suggest $70 \%$, or $50 \% .33-$ ${ }^{35}$ In our study, most of the questions reached a consensus $\geq 70 \%$, and all of them had a consensus $\geq 50 \%$.
In the first round, there was no consensus in $37 \%$ of the questions, which shows a high degree of disagreement among the consulted experts. Most of the questions that did yield consensus were related to dose adjustment based on the results of patients' INR without evidence of hemorrhage and time for reassessment. On the other hand, consensus was reached in all questions related to clinical management whenever the patient has hemorrhage, demonstrating agreement to procedures among health professionals when the patient experiences a serious adverse event.

By resubmitting the questions, consensus was reached in only $25 \%$, related to procedure and period for dose adjustment. This low agreement rate in the responses was expected since those were questions that depended greatly on the clinical experience of each medical expert.

In the third round, including eight questions, consensus was reached in two questions. Unfortunately, questions related to procedure and period for dose adjustments did not reach consensus. However, if a 50\% agreement rate was considered in the third round, a consensus would be reached for all questions.

Therefore, out of 27 initial questions, only six questions failed to reach $\geq 70 \%$ consensus, which proves the applicability of this method for developing algorithms for monitoring the use of warfarin, in which the main questions about the pharmacotherapy of this drug could be solved.

\section{Study limitations}

Our study was conducted based on the subjective reasoning of the experts. Thus, besides the frequent disagreement in responses between the consulted health professionals, other experts who were not included in our study may not agree with the results obtained.

\section{Conclusion}

We were able to develop algorithms for monitoring the use of warfarin by medical experts using the Delphi Method. Since this method is inexpensive and involves the participation of experts, it has proved adequate for the intended purpose.

Further studies are needed to validate the algorithms developed in our research, enabling them to be used in clinical practice.

\section{ACKNOWLEDGMENTS}

We gratefully acknowledge all participants for taking their time to complete this survey.

\section{Conflict of interest}

The authors declare no conflict of interest. 


\section{ResUmo}

Algoritmos para monitorar o uso de varfarina: resultados do método Delphi

A varfarina é o anticoagulante oral mais prescrito. Novos anticoagulantes orais foram recentemente aprovados; porém, o uso é restrito e as técnicas de reversibilidade do efeito anticoagulante ainda são pouco conhecidas. Assim, este estudo propõe o desenvolvimento de um algoritmo para o monitoramento terapêutico de pacientes em uso de varfarina, com base na opinião de médicos que utilizam esse fármaco na prática clínica. O desenvolvimento do algoritmo foi realizado em dois estágios: (i) revisão da literatura e (ii) avaliação do algoritmo por médicos, segundo o método Delphi. Com base na análise dos artigos, dois algoritmos foram desenvolvidos: "Recomendações para o uso de varfarina na terapia anticoagulante" e "Recomendações para o uso de varfarina na terapia anticoagulante: ajuste de dose e controle de sangramento". Posteriormente, os algoritmos foram analisados por 19 médicos que responderam ao convite e aceitaram participar da pesquisa. Desses, 16 responderam a primeira rodada, 11 , a segunda e oito, a terceira. Houve um consenso de $70 \%$ ou mais na maioria das questões e 50\% para seis questões. Assim, foi possível desenvolver algoritmos para o monitoramento do uso de varfarina por médicos, utilizando o método Delphi. O método proposto é de baixo custo e envolve a participação de médicos especialistas, revelando-se adequado para o fim pretendido. Mais estudos são necessários para validar esses algoritmos, permitindo que eles sejam usados na prática clínica.

Palavras-chave: técnica Delfos, varfarina, tomada de decisões, conduta do tratamento medicamentoso.

\section{References}

1. Mueller RL, Scheidt S. History of drugs for thrombotic disease. Discovery, development, and directions for the future. Circulation. 1994; 89(1):432-49.

2. Liao Z, Feng S, Ling P, Zhang G. Meta-analysis of randomized controlled trials reveals an improved clinical outcome of using genotype plus clinical algorithm for warfarin dosing. J Thromb Thrombolysis. 2014; 39(2):228-34.

3. Johnson JA, Cavallari LH. Warfarin pharmacogenetics. Trends Cardiovasc Med. 2015; 25(1):33-41.

4. Ma TK, Yan BP, Lam YY. Dabigatran etexilate versus warfarin as the oral anticoagulant of choice? A review of clinical data. Pharmacol Ther. 2011; 129(2):185-94.

5. Tran A, Cheng-Lai A. Dabigatran etexilate: the first oral anticoagulant available in the United States since warfarin. Cardiol Rev. 2011; 19(3):154-61.

6. Fellows SE, Rosini JM, Curtis JA, Volz EG. Hemorrhagic gastritis with dabigatrana in a patient with renal insufficiency. J Emerg Med. 2013; 44(2):e221-5.

7. Meeting Report. Oral anticoagulants: will safety be the distinguishing factor? Reactions Weekly. 2012;1403:3-4.

8. Cheng JW, Vu H. Dabigatran etexilate: an oral direct thrombin inhibitor for the management of thromboembolic disorders. Clin Ther. 2012; 34(4):766-87.

9. Eikelboom JW, Wallentin L, Connolly SJ, Ezekowitz M, Healey JS, Oldgren $\mathrm{J}$, et al. Risk of bleeding with 2 doses of dabigatran compared with warfarin in older and younger patients with atrial fibrillation: an analysis of the randomized evaluation of long-term anticoagulant therapy (RE-LY) trial Circulation. 2011; 123(21):2363-72.

10. Sun D, Lazo-Langner A. New oral anticoagulants. CMAJ. 2013; 185(4):E212

11. Lip GY, Ponikowski P, Andreotti F, Anker SD, Filippatos G, Homma S, et al; ESC Task Force. Thrombo-embolism and antithrombotic therapy for heart failure in sinus rhythm. A joint consensus document from the ESC Heart Failure Association and the ESC Working Group on Thrombosis. Eur J Heart Fail. 2012; 14(7):681-95.

12. Garcia D, Libby E, Crowther MA. The new oral anticoagulants. Blood. 2010; 115(1):15-20

13. Baker RI, Coughlin PB, Gallus AS, Harper PL, Salem HH, Wood EM; Warfarin Reversal Consensus Group. Warfarin reversal: consensus guidelines, on behalf of the Australasian Society of Thrombosis and Haemostasis. Med J Aust. 2004; 181(9):492-7.

14. Vats V, Nutescu EA, Theobald JC, Wojtynek JE, Schumock GT. Survey of hospitals for guidelines, policies and protocols for anticoagulants. Am J Health Syst Pharm. 2007; 64(11):1203-8.

15. Atallah AN, Castro AA. Medicina baseada em evidências: o elo entre a boa ciência e a boa prática clínica. Diagn Tratamento. 1998; 3(2):50-8

16. Weingarten $\mathrm{S}$. Translating practice guidelines into patient care: guidelines at the bedside. Chest. 2000; 118(2 Suppl):4S-7S.

17. Smith WR. Evidence for the effectiveness of techniques to change physician behavior. Chest. 2000; 118(2 Suppl):8S-17S.

18. Piola SF, Vianna SM, Vivas-Consuelo D. Estudo Delphi: atores sociais e tendências do sistema de saúde brasileiro. Cad Saúde Pública. 2002; 18(Suppl):181-90.

19. Steurer J. The Delphi method: an efficient procedure to generate knowledge. Skeletal Radiol. 2011; 40(8):959-61.

20. Wright JTC, Giovinazzo RA. Delphi: uma ferramenta de apoio ao planejamento prospectivo. Cad Pesq Administração. 2000; 1(12):54-65

21. Kennedy HP. Enhancing Delphi research: methods and results. J Adv Nurs. 2004; 45(5):504-11.

22. Tan GM, Wu E, Lam YY, Yan BP. Role of warfarin pharmacogenetic testing in clinical practice. Pharmacogenomics. 2010; 11(3):439-48.

23. Suarez-Kurtz G, Paula DP, Struchiner CJ. Pharmacogenomic implications of population admixture: Brazil as a model case. Pharmacogenomics. 2014; 15(2):209-19.

24. Kimmel SE, French B, Kasner SE, Johnson JA, Anderson JL, Gage BF, et al.; COAG Investigators. A pharmacogenetic versus a clinical algorithm for warfarin dosing. N Engl J Med. 2013; 369(24):2283-93.

25. Ekladious SM, Issac MS, El-Atty Sharaf SA, Abou-Youssef HS. Validation of a proposed warfarin dosing algorithm based on the genetic make-up of Egyptian patients. Mol Diagn Ther. 2013; 17(6):381-90.

26. Limdi NA, McGwin G, Goldstein JA, Beasley TM, Arnett DK, Adler BK, et al. Influence of CYP2C9 and VKORC1 1173C/T genotype on the risk of hemorrhagic complications in African-American and European-American patients on warfarin. Clin Pharmacol Ther. 2008; 83(2):312-21.

27. Stergiopoulos K, Brown DL. Genotype-guided vs clinical dosing of warfarin and its analogues: meta-analysis of randomized clinical trials. JAMA Inter Med. 2014; 174(8):1330-8.

28. Scott SA, Lubitz SA. Warfarin pharmacogenetic trials: is there a future for pharmacogenetic-guided dosing? Pharmacogenomics. 2014; 15(6):719-22.

29. Keeney S, Hasson F, McKenna HP. A critical review of the Delphi technique as a research methodology for nursing. Int J Nurs Stud. 2001; 38(2):195-200.

30. Okoli C, Pawlowski SD. The Delphi method as a research tool: an example, design considerations and applications. Inform \& Manag. 2004; 42(1):15-29.

31. Álvarez I, Calvo JA, Mora A. Involving academics in the accounting standard setting process: an application of the Delphi methodology to the assessment of IASB proposals. J Manag Governance. 2012; 18(3):765-91.

32. Diamond IR, Grant RC, Feldman BM, Pencharz PB, Ling SC, Moore AM, et al. Defining consensus: a systematic review recommends methodologic criteria for reporting of Delphi studies. J Clin Epidemiol. 2014; 67(4):401-9.

33. Loughlin $\mathrm{K}$, Moore L. Using Delphi to achieve congruent objectives and activities in a pediatrics department. J Med Educ. 1979; 54(2):101-6.

34. Hasson F, Keeney S, McKenna H. Research guidelines for the Delphi survey technique. J Adv Nurs. 2000; 32(4):1008-15.

35. Green B, Jones M, Hughes D, Williams A. Applying the Delphi technique in a study of GPs' information requirements. Health Soc Care Community. 1999; 7(3):198-205 